\title{
INFLUÊNCIA DO SUBSTRATO NA GERMINAÇÃO E DESENVOLVIMENTO INICIAL DE PLANTAS DE MARACUJAZEIRO AMARELO (Passiflora edulis Sims f. flavicarpa Deg)
}

\author{
Effects of substrate on germination and initial growth of yellow passion fruit \\ (Passiflora edulis Sims f. flavicarpa Deg)
}

\author{
Américo Wagner Júnior ${ }^{1}$, Rodrigo Sobreira Alexandre ${ }^{1}$, Jacson Rondinelli da Silva Negreiros ${ }^{2}$, \\ Leonardo Duarte Pimentel ${ }^{3}$, José Osmar da Costa e Silva ${ }^{3}$,Claudio Horst Bruckner ${ }^{4}$
}

\begin{abstract}
RESUMO
Na maioria das vezes, a muda de maracujazeiro amarelo é produzida a partir de sementes. Neste sentido, o êxito no estabelecimento da cultura depende de vários fatores, entre os quais está a utilização de sementes de boa qualidade e a escolha do melhor substrato. Com este trabalho, objetivou-se avaliar a influência de quatro substratos na germinação e desenvolvimento inicial de plantas de maracujazeiro amarelo (Passiflora edulis Sims f. flavicarpa Deg), cultivar IAC 277. O trabalho foi realizado no Departamento de

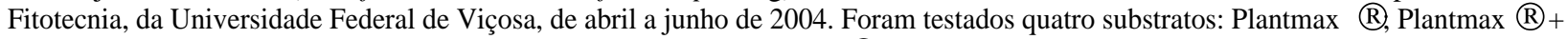
Areia (1:1 v/v); Plantmax ®) Latossolo Vermelho (1:1 v/v); Plantmax $®+$ Latossolo Vermelho + Areia (1:1:1 v/v). Foi utilizado o delineamento experimental em blocos casualizados, com quatro tratamentos e três repetições, considerando-se como unidade experimental, cada 5 recipientes plásticos. Após 48 dias da semeadura foram analisados: porcentagem de germinação; comprimento total, da parte aérea e de raiz das plantas e a massa da matéria seca total das plantas. Os dados foram submetidos à análise de variância e ao teste de Tukey $(\mathrm{a}=0,05)$. Pelos resultados obtidos não foram observadas diferenças significativas entre os substratos em todas as variáveis analisadas. Com isso, conclui-se que os quatros substratos utilizados proporcionaram condições adequadas à germinação e ao desenvolvimento inicial de plantas de maracujazeiro amarelo, cultivar IAC 277.
\end{abstract}

Termos para indexação: Maracujá amarelo, propagação sexuada, emergência, muda, Passiflora edulis f. flavicarpa.

\begin{abstract}
Most of the time, seedlings of yellow passion fruit are produced from seeds. The success in the establishment of the culture depends on several factors, such as the use of seeds of good quality and choice of the best substrate. This work had the objective of evaluating the influence of four substrates on the germination and initial seedling growth of yellow passion fruit (Passiflora edulis Sims f. flavicarpa Deg), cv. IAC 277. The work was carried out at the Department of Plant Science, of the Federal University of

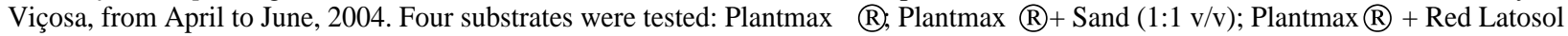
$(1: 1 \mathrm{v} / \mathrm{v})$; Plantmax $\mathbb{Q}+$ Red Latosol + Sand $(1: 1: 1 \mathrm{v} / \mathrm{v})$. The experimental design was a completely randomized block, with three replications, where each plot was constituted by five plastic bags. After 48 days of sowing, the percentage of germination; total length of seedlings (roots and above ground) and seedlings dry weight, were evaluate. Data were submitted to analysis of variance and means compared by Tukey test $(a=0.05)$. Significant differences were not observed among the substrates for all evaluated characteristics. This indicates that the four substrates used provided appropriate conditions for germination and the initial development of yellow passion fruit seedlings, cv. IAC 277.
\end{abstract}

Index terms: Yellow passion fruit, sexual propagation, emergence, seedling, Passiflora edulis f. flavicarpa.

(Recebido para publicação em 19 de abril de 2005 e aprovado em 7 de outubro de 2005)

\section{INTRODUÇÃO}

O termo maracujazeiro é a denominação genérica de cerca de 500 espécies de maracujá, a maioria nativa da América tropical. Apesar disso, os cultivos comerciais do País baseia-se numa única espécie, Passiflora edulis Sims f. flavicarpa Deg, também conhecida como maracujáamarelo ou azedo (BRUCKNER et al., 2002).
Esta espécie pode ser propagada de forma sexuada, por meio de sementes, e assexuada, pela utilização da estaquia, enxertia, alporquia e cultura de tecidos "in vitro". Porém, na maioria das vezes, a muda é produzida a partir de sementes (FERREIRA et al., 2001).

Neste sentido, o êxito no estabelecimento da cultura depende de vários fatores, entre os quais está a utilização

\footnotetext{
${ }^{1}$ Engenheiro Agrônomo MSc. Doutorando em Fitotecnia - Universidade Federal de Viçosa/UFV - 36571-000 - Viçosa, MG - Bolsista CNPq americowagner@ibest.com.br

²Engenheiro Agrônomo MSc. Doutorando em Genética e Melhoramento - Universidade Federal de Viçosa/UFV - 36571-000 - Viçosa, MG - Bolsista Capes - jacson@vicosa.ufv.br

${ }^{3}$ Graduando do curso de Agronomia, Universidade Federal de Viçosa/UFV - 36571-000 - Viçosa, MG - Bolsista CNPq - agropimentel@yahoo.com.br ${ }^{4}$ Engenheiro Agrônomo DS., Professor Titular do Departamento de Fitotecnia - Universidade Federal de Viçosa/UFV - $36571-000$ - Viçosa, MG bruckner@ufv.br
} 
de sementes de boa qualidade e a escolha do melhor substrato. $\mathrm{O}$ substrato a ser utilizado exerce grande influência sobre a emergência de plantas e formação das mudas de boa qualidade.

O substrato pode ser formado de matéria-prima de origem mineral, orgânica ou sintética, de um só material ou de diversos materiais em misturas, sendo que alguns não possuem características desejáveis de qualidade (KANASHIRO, 1999).

A germinação das sementes é influenciada pelo substrato, pois fatores como aeração, estrutura, capacidade de retenção de água, grau de infestação de patógenos, entre outros, podem variar de acordo com o material utilizado, favorecendo ou prejudicando a germinação das sementes.

O substrato ideal deve ser de fácil disponibilidade de aquisição e transporte, ausência de patógenos e plantas daninhas, riqueza em nutrientes essenciais, $\mathrm{pH}$ adequado, boa textura e estrutura (SILVA et al., 2001), além de manter uma proporção adequada entre a disponibilidade de água e aeração (POPINIGIS, 1985).

Um dos materiais que podem ser empregados na formação de mudas de maracujazeiro é o substrato comercial Plantmax ${ }^{\circledR}$, sendo este elaborado com vermiculita expandida e materiais orgânicos de origem vegetal, isento de pragas, microrganismos e sementes de invasoras (RAMOS et al., 2002).

Entretanto, dificilmente um material sozinho apresentará todas as características desejáveis para formação de mudas. Nesse sentido, é preferível misturar dois ou mais materiais para a obtenção de um substrato adequado a uma determinada espécie (BIASI et al., 1995).

Com este trabalho, objetivou-se avaliar a influência de quatro substratos na germinação e desenvolvimento inicial de plantas de maracujazeiro amarelo (Passiflora edulis Sims f. flavicarpa Deg), cultivar IAC 277.

\section{MATERIAL E MÉTODOS}

O trabalho foi realizado no Departamento de Fitotecnia da Universidade Federal de Viçosa, Minas Gerais, de abril a junho de 2004. As sementes utilizadas foram extraídas de frutos maduros de maracujazeiro (P. edulis $\mathrm{f}$. flavicarpa), cultivar IAC 277.

Para extração das sementes, os frutos foram seccionados pela metade. A retirada do arilo foi realizada manualmente, através de fricção em peneira de malha fina, acrescentando-se cal virgem. Após a remoção do arilo, as sementes foram lavadas em água corrente e dispostas em papel toalha, mantendo-as à sombra para secagem.
Posteriormente, no interior da casa-de-vegetação, procedeu-se a semeadura de duas sementes em recipiente plástico com capacidade de 1 litro a $1,0 \mathrm{~cm}$ de profundidade. Foram utilizados quatro diferentes substratos: Plantmax ®(S1); Plantmax ®+ Areia (S2 - 1:1 $\mathrm{v} / \mathrm{v})$; Plantmax ${ }^{\circledR}+$ Latossolo Vermelho $(\mathrm{S} 3-1: 1 \mathrm{v} / \mathrm{v})$; Plantmax® + Latossolo Vermelho + Areia (S4 - 1:1:1 v/v). As características químicas dos substratos são apresentadas na Tabela 1. Após a germinação, as plantas foram desbastadas, deixando apenas a mais vigorosa por recipiente plástico. A irrigação foi ministrada diariamente, com maior freqüência nos primeiros dias após a semeadura.

Foi utilizado o delineamento experimental em blocos casualizados, com quatro tratamentos e três repetições, considerando-se como unidade experimental, cada 5 recipientes plásticos.

As avaliações foram realizadas 48 dias após a instalação do experimento. As variáveis analisadas foram: porcentagem de germinação (\%); comprimento total das plantas $(\mathrm{cm})$; comprimento da parte aérea $(\mathrm{cm})$; comprimento de raiz $(\mathrm{cm})$ e a massa da matéria seca total das plantas $(\mathrm{g})$.

Os dados foram submetidos à análise de variância e ao teste de Tukey $(a=0,05)$. Os dados das porcentagens de germinação foram transformados segundo arco seno $\sqrt{\mathrm{x} / 100}$. Já os demais dados não sofreram transformação.

Para determinação do comprimento total, da parte aérea e de radícula das plantas, as mesmas foram retiradas dos substratos, cuidadosamente, lavadas em água e medidas com auxílio de uma régua graduada em milímetros. Posteriormente, para obtenção da massa da matéria seca total, todas as plantas de cada tratamento e repetição foram colocadas em envelopes de papel e transferidas para estufa com circulação de ar a $60^{\circ} \mathrm{C}$, permanecendo até atingirem peso constante, sendo assim obtido em 72 horas.

As temperaturas do ar, mínima e máxima foram obtidas diariamente no interior da casa-de-vegetação (Figura 1), sendo as médias de $17,98^{\circ} \mathrm{C}, 14,35^{\circ} \mathrm{C}$ e $23,96^{\circ} \mathrm{C}$, respectivamente.

\section{RESULTADOS E DISCUSSÃO}

O processo de germinação das sementes teve inicio vinte dias após a semeadura, sendo observado, nos quatro substratos, $100 \%$ de germinação aos vinte e seis dias.

Segundo São José (1991), nas condições brasileiras a germinação ocorre entre 2 e 4 semanas após a semeadura, dependendo das condições climáticas, sendo que no verão o período de germinação é menor e no inverno maior. 
TABELA 1 - Características químicas dos quatro substratos utilizados na germinação e desenvolvimento inicial de plantas de maracujazeiro-amarelo. Universidade Federal de Viçosa, Viçosa - MG, 2004.

\begin{tabular}{|c|c|c|c|c|c|c|c|c|c|c|c|}
\hline Substrato & $\begin{array}{c}\text { pH } \\
\mathrm{H}_{2} \mathrm{O}\end{array}$ & $\begin{array}{l}\mathbf{P} \\
\mathbf{m g}\end{array}$ & $\begin{array}{c}K \\
n^{-3}\end{array}$ & $\mathrm{Ca}^{2+}$ & $\mathbf{M g}^{2+}$ & $\mathbf{A l}^{3+}$ & $\begin{array}{r}\mathrm{H}+\mathrm{Al} \\
\text { cmolc dr }\end{array}$ & SB & $\begin{array}{c}\text { CTC } \\
(\mathbf{t})\end{array}$ & $\begin{array}{c}\text { CTC } \\
\text { (T) }\end{array}$ & $\begin{array}{l}\mathrm{V} \\
\%\end{array}$ \\
\hline $\mathrm{S} 1^{\mathrm{a}}$ & 5,47 & 662,1 & 600 & 9,64 & 3,95 & 0,0 & 6,9 & 15,12 & 15,12 & 22,02 & 68,7 \\
\hline $\mathrm{S} 2^{\mathrm{a}}$ & 5,5 & 115,1 & 210 & 4,0 & 1,7 & 0,0 & 6,60 & 6,24 & 6,24 & 12,84 & 49,0 \\
\hline $\mathrm{S}^{\mathrm{a}}$ & 6,1 & 104,9 & 250 & 5,0 & 1,7 & 0,0 & 4,62 & 7,34 & 7,34 & 11,96 & 61,0 \\
\hline $\mathrm{S} 4^{\mathrm{a}}$ & 5,7 & 92,0 & 270 & 5,7 & 2,0 & 0,0 & 7,26 & 8,39 & 8,39 & 15,65 & 54,0 \\
\hline
\end{tabular}

${ }^{a}\left(\right.$ S1) Plantmax ${ }^{\circledR} ;\left(\right.$ S2) Plantmax ${ }^{\circledR}+$ Areia $-1: 1$ v/v; (S3) Plantmax ${ }^{\circledR}+$ Latossolo Vermelho - 1:1 v/v; (S4) Plantmax ${ }^{\circledR}+$ Latossolo Vermelho + Areia - 1:1:1 v/v.

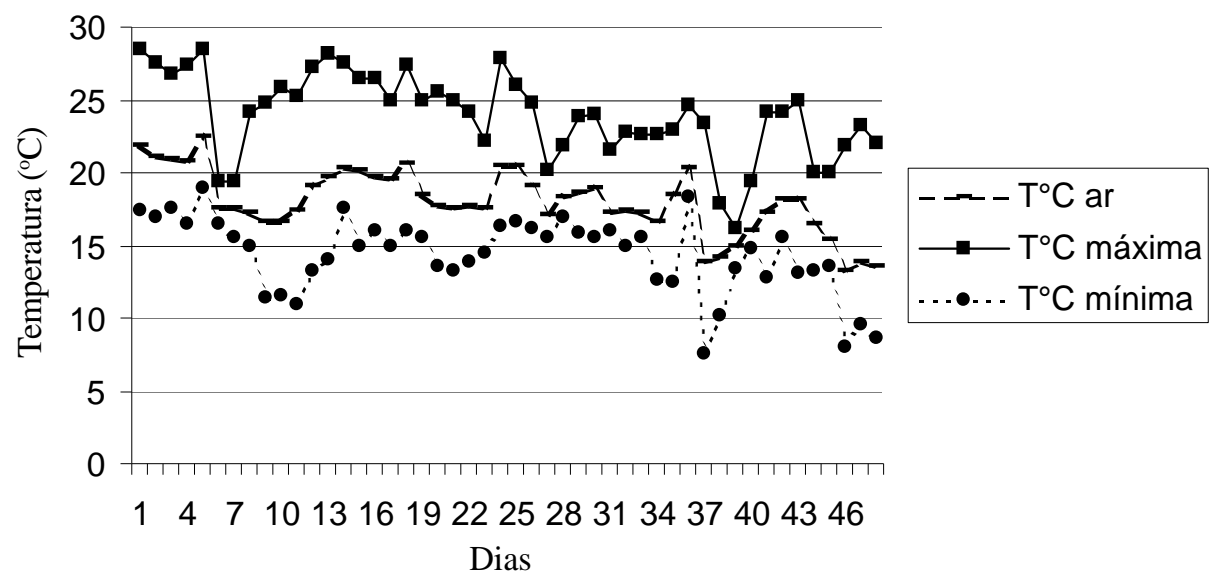

FIGURA 1 - Leituras médias diárias das temperaturas uo ar, mínimas e máximas durante a execução do experimento. Universidade Federal de Viçosa, Viçosa - MG, 2004.

Apesar do substrato Plantmax® apresentar os maiores teores de $\mathrm{P}, \mathrm{K}$ e Ca (Tabela 1), que são os macronutrientes, juntamente com o nitrogênio, mais extraídos pela cultura do maracujazeiro (SILVA \& OLIVEIRA, 2000), não foram observadas diferenças significativas entre os substratos em todas as variáveis analisadas (Tabela 2). Provavelmente, os teores de nutrientes foram suficientes em todos os substratos não evidenciando efeito dos tratamentos, apesar da maior concentração de macronutrientes no substrato Plantmax $®$.

Segundo Ramos et al. (2002), um bom substrato é aquele que objetiva proporcionar condições adequadas à germinação e/ou ao surgimento ou ainda ao desenvolvimento do sistema radicular da muda em formação.

De acordo com os resultados, os quatros substratos utilizados proporcionaram condições adequadas à germinação e ao desenvolvimento inicial da planta.

Em pesquisa realizada por Ferreira (1996), foi possível verificar que as espécies $P$. alata Dryander, $P$. edulis f. flavicarpa, P. giberti N.E.Br. e P. caerulea L. apresentam comportamentos distintos em diversos substratos estudados, sendo que a espécie de P. edulis $\mathrm{f}$. flavicarpa apresenta melhor adaptação a diversos substratos. Supondo-se também que esta característica de melhor adaptação possa ter influenciado os resultados obtidos no presente trabalho, principalmente, por tratar-se de uma cultivar melhorada ('IAC 277').

Lopes et al. (1996) e Silva et al. (2001), analisando a influência de diversos substratos no desenvolvimento de mudas de maracujazeiro amarelo, observaram que o substrato comercial Plantmax $₫$ foi superior à Vermiculita $\AA$ em todas as características analisadas nas plantas. 
TABELA 2 - Porcentagem de germinação, comprimento total das plantas, comprimento da parte aérea, comprimento de radícula, massa da matéria seca total das plantas de maracujazeiro amarelo 'IAC 277', em quatro substratos. Universidade Federal de Viçosa, Viçosa - MG, 2004.

\begin{tabular}{cccccc}
\hline Substrato & $\begin{array}{c}\text { Germinação } \\
(\%)\end{array}$ & Comp.total $(\mathbf{c m})$ & $\begin{array}{c}\text { Comp. parte } \\
\text { aérea }(\mathbf{c m})\end{array}$ & $\begin{array}{c}\text { Comp. radícula } \\
(\mathbf{c m})\end{array}$ & MS total $(\mathbf{g})$ \\
\hline $\mathrm{S} 1^{\mathrm{a}}$ & $100^{\mathrm{ns}}$ & $10,39^{\mathrm{ns}}$ & $3,64^{\mathrm{ns}}$ & $6,75^{\mathrm{ns}}$ & $0,14^{\mathrm{ns}}$ \\
$\mathrm{S}^{\mathrm{a}}$ & 100 & 9,28 & 3,21 & 6,07 & 0,14 \\
$\mathrm{~S}^{\mathrm{a}}$ & 100 & 9,98 & 3,74 & 6,24 & 0,13 \\
$\mathrm{~S}^{\mathrm{a}}$ & 100 & 10,03 & 3,69 & 6,34 & 0,15 \\
\hline $\mathrm{CV}(\%)$ & 0 & 9,39 & 9,24 & 14,52 & 25,88 \\
\hline
\end{tabular}

a(S1) Plantmax ${ }^{\circledR}$; (S2) Plantmax ${ }^{\circledR}+$ Areia - 1:1 v/v; (S3) Plantmax ${ }^{\circledR}+$ Latossolo Vermelho - 1:1 v/v; (S4) Plantmax ${ }^{\circledR}$ + Latossolo Vermelho + Areia - 1:1:1 v/v.

Lima et al. (1994), estudando o efeito da relação solo e esterco de bovino, concluíram que, as misturas solo e esterco nas proporções de 2:1, 1:1 e 3:1, proporcionaram maiores comprimentos da parte aérea de plantas de maracujazeiro amarelo, em recipientes plásticos.

Em outro estudo, Negreiros et al. (2003) verificaram 90 dias após a semeadura que o substrato contendo Plantmax $\AA$, esterco de curral, solo e areia (1:1:1:1 v/v) é uma boa alternativa para formação de mudas de maracujazeiro-amarelo.

Já Araújo Neto et al. (2002), avaliando o efeito de diferentes misturas de substratos e recipientes, observaram que as misturas contendo esterco de curral, carvão vegetal, terra e areia $(2: 1: 1: 1 \mathrm{v} / \mathrm{v})$ e vermicomposto, terra, carvão vegetal e areia $(1: 1: 1: 1 \mathrm{v} / \mathrm{v})$ proporcionaram melhor desenvolvimento das mudas de maracujazeiro amarelo em recipiente plástico. Contudo, quando estes autores utilizaram tubetes e bandejas de isopor o efeito dessas misturas foram iguais ao substrato comercial Plantmax $® \mathrm{e}$ a mistura Plantmax ${ }^{\circledR}$, carvão vegetal, terra e areia $(1: 1: 1: 1 \mathrm{v} / \mathrm{v})$ apresentou os menores valores em todas as características analisadas, independente do recipiente utilizado.

\section{CONCLUSÃO}

Conclui-se que os quatros substratos utilizados proporcionaram condições adequadas à germinação e ao desenvolvimento inicial de plantas de maracujazeiro amarelo, cultivar IAC 277.

\section{REFERÊNCIAS BIBLIOGRÁFICAS}

ARAÚJO NETO, S. E. de; RAMOS, J. D.; MENDONÇA, V.; GONTIJO, T. C. A.; PIO, R.; MARTINS, P. C. C. Desenvolvimento de mudas de maracujazeiro-amarelo em diferentes substratos e recipientes. In: CONGRESSO
BRASILEIRO DE FRUTICULTURA, 2002, Belém. Resumo Expandido... Belém: Sociedade Brasileira de Fruticultura, 2002. CD-ROM.

BIASI, L. A.; BILIA, D. A. C.; SÃO JOSÉ, A. R.; FORNASIERI, J. L.; MINAMI, K. Efeito de misturas de turfa e bagaço de cana sobre a produção de mudas de maracujá e tomate. Scientia Agrícola, Piracicaba, v. 2, n. 52, p. 239-243, 1995.

BRUCKNER, C. H.; MELETTI, L. M. M.; OTON, W. C.; ZERBINI JÚNIOR, F. M. Maracujazeiro. In: BRUCKNER, C. H. Melhoramento de fruteiras tropicais. Viçosa: UFV, 2002. p. 373-409.

FERREIRA, G. Estudo do desenvolvimento de portaenxertos para maracujá doce (Passiflora alata Dryander) em diversos substratos. 1996. 155 f. Dissertação (Mestrado) - Universidade do Estado de São Paulo, Botucatu, 1996.

FERREIRA, G.; FOGAÇA, L. A.; MORO, E. Germinação de sementes de Passiflora alata Dryander (maracujá-doce) submetidas a diferentes tempos de embebição e concentrações de ácido giberélico. Revista Brasileira de Fruticultura, Jaboticabal, v. 23, n. 1, p. 160-163, 2001.

KANASHIRO, S. Efeito de diferentes substratos na produção da espécie Aechemea fasciata (Lindley) Baker em vasos. 1999. 79 f. Dissertação (Mestrado) - Escola Superior de Agricultura “Luiz de Queiroz”, Piracicaba, 1999.

LIMA, A. de A.; BORGES, A. L.; CALDAS, R. C. Substratos para produção de mudas de maracujazeiro. In: CONGRESSO BRASILEIRO DE FRUTICULTURA, 13., 1994, Salvador. Anais... Salvador: SBF, 1994. v. 3, p. 808-809. 
LOPES, P. S. N.; RAMOS, J. D.; CARVALHO, J. G. de; MORAIS, A. R. de. Efeito da adubação nitrogenada e substratos no crescimento de mudas de maracujazeiro azedo em tubetes. In: CONGRESSO BRASILEIRO DE FRUTICULTURA, 14., 1996, Curitiba. Anais... Curitiba: SBF, 1996. p. 342.

NEGREIROS, J. R. S.; ÁLVARES, V. S.; BRAGA, L. R.; BRUCKNER, C. H. Diferentes substratos na formação de mudas de maracujazeiro-amarelo. Revista Ceres, Viçosa, v. 51, n. 294, p. 243-249, 2003.

POPINIGIS, F. Fisiologia da semente. 2. ed. Brasília, DF: [s.n.], 1985. 289 p.

RAMOS, J. D.; CHALFUN, N. N. J.; PASQUAL, M.; RUFINI, J. C. M. Produção de mudas de plantas frutíferas por semente. Informe Agropecuário, Belo Horizonte, v. 23, n. 216, p. 64-72, 2002.

SÃO JOSÉ, A. R. Propagação do maracujazeiro. In: SÃO JOSÉ, A. R.; FERREIRA, F. R.; VAZ, R. L. A cultura do maracujá no Brasil. São Paulo: UNESP, 1991. p. 25-41.

SILVA, J. R.; OLIVEIRA, H. J. Nutrição e adubação do maracujazeiro. Informe Agropecuário, Belo Horizonte, v. 21, n. 206, p. 52-58, 2000.

SILVA, R. P. da; PEIXOTO, J. R.; JUNQUEIRA, N. T. V. Influência de diversos substratos no desenvolvimento de muda de maracujazeiro-azedo (Passiflora edulis Sims $\mathrm{f}$. flavicarpa Deg). Revista Brasileira de Fruticultura, Jaboticabal, v. 23, n. 2, p. 377-381, 2001. 